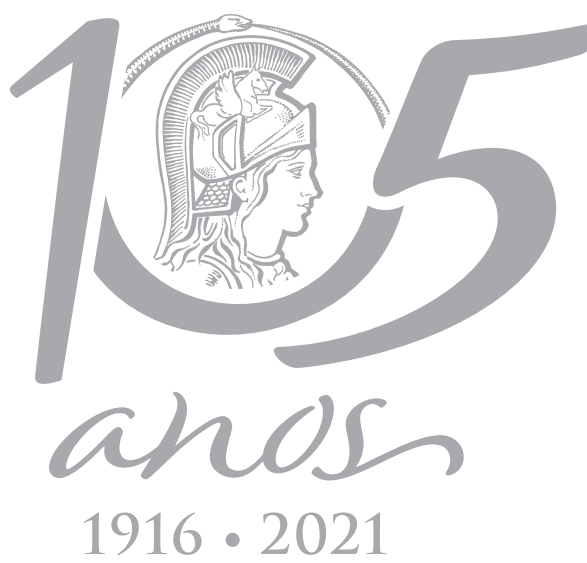

An Acad Bras Cienc (2022) 94(1): e20200512 DOI 10.1590/0001-3765202120200512

Anais da Academia Brasileira de Ciências | Annals of the Brazilian Academy of Sciences Printed ISSN 0001-3765 I Online ISSN 1678-2690

www.scielo.br/aabc | www.fb.com/aabcjournal

PHYSICAL SCIENCES

\title{
Characterization of Cuban and Brazilian natural zeolites by photoacoustic spectroscopy and electron paramagnetic resonance
}

\author{
ARLEM LARA-BERNAL, MARCELO G. DA SILVA, LEONARDO MOTA, ERNESTO MARÍN, \\ THALLIS C. CORDEIRO, EDSON C. DA SILVA, DANIEL A. VIANA, HELION VARGAS, \\ JOSÉ CARLOS POLIDORO \& MARISA B.M. MONTE
}

\begin{abstract}
This report describes the photoacoustic and electron paramagnetic resonance investigations of Brazilian and Cuban zeolites. Photoacoustic optical absorption measurements indicate the presence of iron $\left(\mathrm{Fe}^{3+}\right)$ ions with their respective transition bands for both zeolites. Two species of manganese $\left(\mathrm{Mn}^{2+}\right.$ and $\left.\mathrm{Mn}^{3+}\right)$ were identified in the Cuban sample and the electronic transitions assigned. Iron and manganese ions were confirmed through nonradiative relaxation $(\tau)$ and characteristic diffusion $\left(\tau_{\beta}\right)$ times evaluation, whose values were found to be $\tau_{\mathrm{BRA}}=5.40 \mathrm{~ms}, \tau_{\mathrm{CUB}}=4.60 \mathrm{~ms}, \tau_{\beta B R A}=387$ $\mu \mathrm{S}$ and $\tau_{\beta C U B}=305 \mu \mathrm{s}$. Crystal field $\left(\mathrm{Dq}^{-}{ }_{\mathrm{BRA}} / \mathrm{Dq}^{-}{ }_{\mathrm{CUB}}=1048 \mathrm{~cm}^{-1} / 945 \mathrm{~cm}^{-1}\right)$ plus Racah $\left(B_{-B R A} / B_{-}{ }_{C U B}=457 \mathrm{~cm}^{-1} / 813 \mathrm{~cm}^{-1}\right.$ and $\left.C_{-B R A} / C_{-}{ }_{C U B}=3655 \mathrm{~cm}^{-1} / 2496 \mathrm{~cm}^{-1}\right)$ parameters were assessed as well. Paramagnetic resonance corroborated $\mathrm{Fe}^{3+}$ ions present in the Brazilian zeolite occupying sites showing axial and/or rhombic symmetry distortions. For the Cuban sample, results reveal the characteristic hyperfine sextet lines of $\mathrm{Mn}^{2+}$ overlapping the $\mathrm{Fe}^{3+}$ line. Values of Lande factor and isotropic hyperfine splitting constant were found to be 2.0 and $9.7 \mathrm{mT}$, respectively. This tells us that the $\mathrm{Mn}^{2+}$ lies in octahedral symmetry probably replacing calcium ions and point towards an ionic bonding character of the $\mathrm{Mn}^{2+}$ and its surroundings.
\end{abstract}

Key words: Characteristic diffusion time, natural zeolites, nonradiative relaxation time, phase resolved method, Racah parameters.

\section{INTRODUCTION}

Zeolites can be both natural or synthetic and their definition, strictly speaking, embraces only hydrated crystalline aluminosilicates formed by $\mathrm{SiO}_{4}$ and $\mathrm{AlO}_{4}$ tetrahedrons linked by oxygen atoms. These structures contain open vessels in the form of channels with diameter ranging from $4.2 \AA$ to $7.4 \AA$ and cages. Zeolites frameworks could accommodate guests (e.g. alkaline metals) in either interstitial or substitutional sites, compensating their negative charges. Therefore, due to the easy exchange of cations at low temperatures, zeolites have been mainly employed as catalyst for petroleum cracking and synthesis of organic compounds. Owing to their porous structures, zeolites have also been used in gas and water/wastewater cleaning processes Breck (1974), Dyer (1988), Luna \& Schuchardt (2001), Krstić et al. (2018). 
Zeolite-like materials have found an interesting application as substrate for nitrogen fertilizers de C. Bernardi et al. (2013), leading to environmental mitigation by reducing nitrogen losses from agricultural activities. Ion exchange underpins the feasibility of extending the stay time of the ammonium ion $\left(\mathrm{NH}_{4}^{+}\right)$within the substrate and then release it slowly into the soil. In this sense, researches have been conducted during the last ten years concerning the use of photoacoustics (PA) to investigate natural zeolites. Some of them deals with PA gas monitoring such as nitrous oxide, methane and carbon dioxide after manures' incorporation into maize field Shah et al. (2018), real-time assessment of rates at which ammonia has been released from solutions containing zeolite plus urea fertilizer with and without urease Bueno et al. (2015), and ammonia volatilization from ammonium sulfate-treated zeolites at crop field temperatures in Brazil Baptista-Filho et al. (2011).

To evaluate and compare the ability of different zeolites, it is necessary to characterize them physically and chemically Stocker et al. (2017). Former works have investigated clinoptilolite by electron paramagnetic resonance (EPR) showing its potential to trap metal ions Biyik \& Tapramaz (2016). Also, a structural investigation of ion exchange of thallium cations in zeolite channels has been carried out through Rietveld analysis Dimowa et al. (2017). A scrutiny (characteristics, physical and chemical properties, formation and classification) of several naturally occurring zeolites has been conducted, as well as their uses, for instance: soil amendment, animal nutrition, mycotoxin control, pesticide, herbicide, insecticide and food production (Eroglu et al. (2017) and references therein). Tran and co-workers reviewed the impact of zeolite addition in concrete matrices. They have found that there are missing strategies in order to overcome drawbacks related with compressive strength, superplasticizer consumption and usage of mineral admixtures Tran et al. (2019).

By means of photoacoustic spectroscopy (PAS), it is possible to detect the absorption spectra of some of the zeolites' constituents; here, iron ( $\mathrm{Fe}^{3+}$ ) and manganese $\mathrm{Mn}^{2+}$ and $\mathrm{Mn}^{3+}$ ions. The PA signal is generated due to the absorption of modulated or pulsed light by absorbing centers followed by nonradiative decay (localized and periodic heating) Vargas \& Miranda (1988), Almond \& Patel (1996). Absorbing centers are distributed throughout the sample, and the heat generated at their locations diffuses toward the sample surface and there gives rise to the acoustic signal, which is detected by a microphone. When there is a time lag between the photoacoustic signals generated by the sample's constituents, the individual spectrum of each constituent can be distinguished using the phase-resolved PAS (PRPAS). Through electron paramagnetic resonance (EPR), the identification and status of the sites of $\mathrm{Fe}^{3+}$ and $\mathrm{Mn}^{2+}$ ions are feasible.

Particularly, Brazilian and Cuban zeolites have been investigated from the point of view of chemical composition (wt\%), textural analysis (specific area, pore volume and mean pore diameter), TPD (temperature programmed $\mathrm{NH}_{3}$ desorption), nitrogen content by Kjeldahl method, structural (x-ray diffraction accompanied by Rietveld refinement), and micro-structural (transmission electron microscopy) characterizations Baptista-Filho et al. (2011), Monte et al. (2009), Baptista-Filho (2011), Riter (2011). Although many properties of natural zeolites have been found hitherto in the literature, as far as the authors know, there are no information about PA assessment of optical transition bands, crystal field and Racah parameters, beyond the determination of nonradiative relaxation and characteristic diffusion times of iron and manganese ions within the zeolite framework. Therefore, this work is intended to cover such lack of data and contribute to the zeolite community providing new results. 


\section{THEORY OF PHASE-RESOLVED METHOD (PRM)}

Phase-resolved photoacoustic spectroscopy (PRPAS) was applied to separate the spectra generated by different chemical constituents of the sample. The separation is accomplished when the absorbing centers, e.g., $A$ and $B$, have different nonradiative relaxation time $\tau$ or/and characteristic diffusion time $\tau_{\beta}$ Baesso et al. (1989), Corrêa et al. (2011), what is closely dependent on how these absorbing centers are depth-distributed into the sample. Thus, a finite time lag between the photoacoustic signals generated by the chemical constituents becomes measurable using a phase-sensitive detection technique. To simplify the understanding of the phase-resolved method, a vector diagram is depicted in Figure 1 , where each vector symbolizes the signal intensity at a specific wavelength $\left(\lambda_{A}\right.$ and $\left.\lambda_{B}\right)$ absorbed preferably by centers $\mathrm{A}$ and $\mathrm{B}$, respectively.

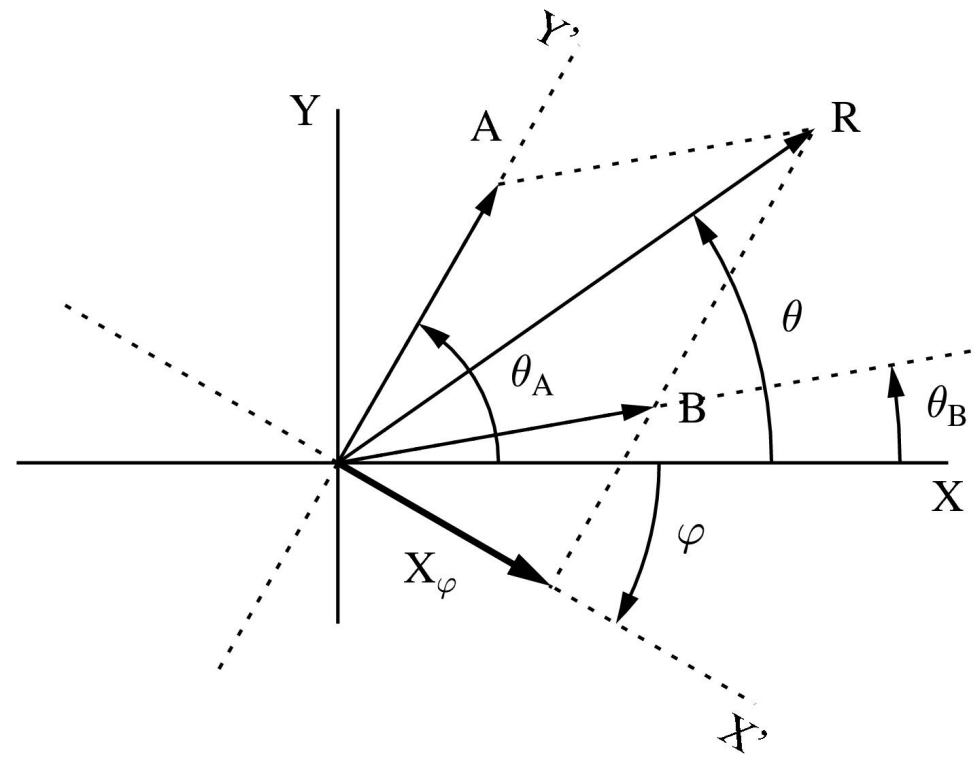

Figure 1. Vector diagram illustrating the PRM method. The resulting signal (vector $\mathbf{R}$ ) is the sum of vectors $\mathbf{A}$ and $B$ and the angles $\vartheta_{A}$ and $\vartheta_{B}$ stand for the phases between the signals $A$ and $B$ with respect to an external reference. $X$ (in-phase signal) and $Y$ (quadrature signal) are the projections of the vector $R$ on the $X$ and $Y$ axes, respectively.

The resulting signal $(\mathbf{R})$ is the sum of vectors $\mathbf{A}$ and $\mathbf{B}$ (signals related to the absorbing centers here identified as $A$ and $B$ ). The angles $\vartheta_{A}$ and $\vartheta_{B}$ are respectively the phases between the signals $\mathbf{A}$ and $\mathbf{B}$ with respect to an external reference. $X$ (in-phase component of the signal) and $Y$ (quadrature component of the signal) are the projections of the vector $\mathbf{R}$ on the $X$ - and $Y$-axis, respectively. To resolve the spectrum in $B$ after registering the signal with the change of the wavelength, the task consists of finding a new reference axes for which the projection of the vector $\mathbf{A}$, for instance, on the new $\mathrm{X}$-axis (or $\mathrm{Y}$-axis) is null. Such procedure might be achieved mathematically by rotating the original reference axes by an angle $\varphi$ in such a way that the projection of the vector $\mathbf{B}$, i.e. $\left(X_{\varphi}\right)$, is just equal to the projection of the vector $\mathbf{R}$, that is, totally free from the contribution of the projection of $\mathbf{A}\left(\mathrm{Y}_{\varphi}\right)$. At a given angle $\varphi$, this condition is achieved when:

$$
\begin{array}{r}
X_{\varphi}=B \cos \left(\vartheta_{B}-\varphi\right)=R \cos (\vartheta-\varphi)= \\
R \cos (\vartheta) \cos (\varphi)+R \sin (\vartheta) \sin (\varphi)= \\
X \cos (\varphi)+Y \sin (\varphi) .
\end{array}
$$


Whenever the condition above is satisfied, the phase between the signals $A$ and the external reference can be determined. As the $X_{\varphi}$ component has no contribution of $A$, the angle between $A$ and the new $X$-axis is $90^{\circ}$. Thus, as shown in the vector diagram (Figure 1), $\varphi+\vartheta_{A}=90^{\circ}$ César et al. $(1984,1985)$, Pessoa-Júnior (1985).

Lock-in amplifiers are based on phase-sensitive detection technique to single out the components of the signal at a specific reference frequency and phase. $X$ and $Y$ represent the in-phase and quadrature components of a signal, respectively, and they are measured directly by the lock-in amplifier. Thereby a spectrum proportional to that generated by one of the absorbing centers is computed through the Equation 1 at a given phase $\varphi$. Nowadays, lock-in amplifier has also the possibility to add a shift $\varphi$ in the phase of the signal and thus record directly the absorption spectrum of a unique chemical specie.

\section{MATERIALS AND METHODS}

\section{Samples}

Powder samples were provided by the Brazilian Agricultural Research Corporation (EMBRAPA): Cuban natural zeolite (clinoptilolite, furnished by "Celta Brasil", Cotia, SP, Brazil) and a Brazilian sedimentary zeolite from a natural occurring mixture of clays, zeolite and quartz extracted from central-northern Brazil Monte et al. (2009). For the sake of simplicity, Cuban and Brazilian zeolites will be labeled as CUB and BRA, respectively.

\section{Photoacoustic spectroscopy (PAS) measurements}

PA experiments were performed exciting the samples by a modulated monochromatic light after passing the collimated beam of $0.6 \mathrm{~kW}$ xenon arc lamp (Oriel Corporation) through a monochromator (Oriel-model 77250). A step-motor was employed to change the incident angle of the radiation beam on the diffraction grating of the monochromator so that the PA spectra were registered scanning the wavelength from $300 \mathrm{~nm}$ to $750 \mathrm{~nm}$. The light was modulated at $17 \mathrm{~Hz}$ by a mechanical chopper (Stanford Research Corporation-SR540) that was driven by the sine output signal from the function generator of the lock-in amplifier (Stanford Research Corporation-SR830). The modulation frequency of the chopper was used as external reference. The PA signal generated by a 2 g powder sample placed inside a conventional PA cell (MTEC Photoacoustics, Inc., Ames, IA, USA) was detected by a condenser microphone located inside the PA cell. The time constant of the lock-in was set at 300 ms and a sampling rate of $1 \mathrm{~Hz}$ was applied. To take into account the dependence of the intensity of the monochromatic light on the wavelength, both $X$ and $Y$ components of the PA spectra were normalized by the $X$ and $Y$ components of a black-body sample. Nonradiative relaxation time $\tau$ and characteristic diffusion time $\tau_{\beta}$ were also determined by varying the modulation frequency of the light source between $20 \mathrm{~Hz}$ and $60 \mathrm{~Hz}$ at a fixed wavelength.

\section{Electron paramagnetic resonance (EPR) measurements}

The EPR measurements were performed at room temperature with a Brucker (Elexys model E500) spectrometer operating at microwave X- and Q-bands. A conventional BRUKER strong pitch (fiberglass, 
carbon, $\mathrm{KCl}$ ) standard $(\mathrm{g}=2.0028)$ was used to calibrate the external magnetic field. The microwave frequency is precisely measured $\left(\delta f=10^{-4} \mathrm{GHz}\right)$ by the spectrometer itself.

\section{RESULTS AND DISCUSSION}

Figure 2 shows the PA spectrum of the BRA zeolite. The PRM applied for three different $\varphi$ values is depicted in Figure 2a, revealing any change in the spectrum profiles. Such behavior is typical for samples with only one absorption center. Gaussian curves representing the optical absorption bands attributed to the electronic transitions of $\mathrm{Fe}^{3+}$ ions Manhães et al. (2002), Mota et al. (2009) were combined to fit the data (Figure $2 b)$. These transitions are assigned to ${ }^{6} A_{1}\left({ }^{6} S\right) \rightarrow{ }^{4} T_{2}\left({ }^{4} D\right),{ }^{6} A_{1}\left({ }^{6} S\right) \rightarrow$ ${ }^{4} T_{2}\left({ }^{4} G\right)$ and ${ }^{6} A_{1}\left({ }^{6} S\right) \rightarrow{ }^{4} T_{1}\left({ }^{4} G\right)$ (labeled from $b_{1}$ to $b_{4}$ in Figure $2 b$ ) with absorption bands centered respectively at $413 \mathrm{~nm}\left(24231 \mathrm{~cm}^{-1}\right.$, Hannoyer et al. (1992)), $522 \mathrm{~nm}\left(19157 \mathrm{~cm}^{-1}\right.$, Gargori et al. (2017)), $568 \mathrm{~nm}\left(17606 \mathrm{~cm}^{-1}\right.$, Karickhoff (1973)) and $645 \mathrm{~nm}$ (15504 cm $\mathrm{cm}^{-1}$, Manhães et al. (2002)). Do data in the literature indicate that bands $b_{2}$ and $b_{3}$ here identified are attributed to the same transition, that is, ${ }^{6} A_{1}\left({ }^{6} S\right) \rightarrow{ }^{4} T_{2}\left({ }^{4} G\right)$. According to the ligand field theory, these transitions are expected for $\mathrm{Fe}^{3+}$ ions located in octahedral or tetrahedral symmetry Sugano et al. (1970) sites. One point which corroborates such assertion is the fact that the BRA zeolite is a natural material whose composition includes, among others, clay minerals Monte et al. (2009); besides, it is well established the presence of iron ions into the Brazilian soil composition Manhães et al. (2002), Mota et al. (2008, 2009), Baptista-Filho et al. (2011).

Figure 3 a shows the measured CUB zeolite spectrum (solid line) and the effect of the PRM using $\varphi$ $=250^{\circ}, 120^{\circ}$, and $90^{\circ}$ values. For these angles, structural changes were observed on the experimental spectrum profile. Contributions of $\mathrm{Fe}^{3+}$ to the optical spectra are resolved for $\varphi=250^{\circ}$ (Figure $3 \mathrm{~b}$ ). Again, four Gaussian curves were used to fit the experimental data and at least three electronic transitions of $\mathrm{Fe}^{+3}$ could be identified at $380 \mathrm{~nm}\left(26316 \mathrm{~cm}^{-1}\right), 485 \mathrm{~nm}\left(20619 \mathrm{~cm}^{-1}\right)$, and $547 \mathrm{~nm}(18282$ $\mathrm{cm}^{-1}$ ). The electronic transitions Hannoyer et al. (1992), Karickhoff (1973), Manhães et al. (2002), Pedro et al. (2009), Sosman et al. (1998) should be assigned to ${ }^{6} A_{1}\left({ }^{6} S\right) \rightarrow{ }^{4} E\left({ }^{4} D\right),{ }^{6} A_{1}\left({ }^{6} S\right) \rightarrow{ }^{4} A_{1}+{ }^{4} E\left({ }^{4} G\right)$, and ${ }^{6} A_{1}\left({ }^{6} S\right) \rightarrow{ }^{4} T_{2}\left({ }^{4} G\right)$ (labeled from $c_{1}$ to $c_{3}$ in Figure $3 b$ ). For CUB zeolite, these electronic transition are centered at lower wavelength values compared to BRA zeolite. Such shift could be probably due to a different electronic screening experienced by $\mathrm{Fe}^{3+}$ ions within uneven zeolitic matrices.

At $\varphi=90^{\circ}$, four Gaussian curves centered at $350 \mathrm{~nm}, 415 \mathrm{~nm}, 491 \mathrm{~nm}$, and $694 \mathrm{~nm}$ were combined to fit the experimental data. According to the literature, the first two bands are related to $\mathrm{Mn}^{2+}$ and the third band is associated with $\mathrm{Mn}^{3+}$. Characterizing $\mathrm{Mn}^{2+}$ in zinc phosphate glass, Ravikumar Ravikumar et al. (2003) associated the bands at $350 \mathrm{~nm}$ and $415 \mathrm{~nm}$ (labeled as $c_{4}$ and $c_{5}$ in Figure 3c) as being due to the ${ }^{6} A_{1 g}(S) \rightarrow{ }^{4} T_{2 g}(D)$ and ${ }^{6} A_{1 g}(S) \rightarrow{ }^{4} A_{1 g}(G)$ electronic transitions, respectively. Whilst Baesso and co-workers investigating soda-lime glasses, have found a broad band centered at $\approx 491 \mathrm{~nm}$ (labeled as $\mathrm{C}_{6}$ ). They attributed this band to $\mathrm{Mn}^{3+}$ ions Baesso et al. (1989).

By means of PAS, the nonradiative relaxation time $\tau$ and the characteristic diffusion time $\tau_{\beta}$ were determined. Figure 4 a shows the PA signal amplitude for the Cuban zeolite as a function of modulation frequency $f$. A linear fit revealed that the PA signal depended on frequency, as $f^{-1}$. For thermally thick samples, that is, samples whose thicknesses are greater than the thermal diffusion length, either thermoelastic bending or thermal dilatation result in the same $f^{-1}$ frequency dependence on the 

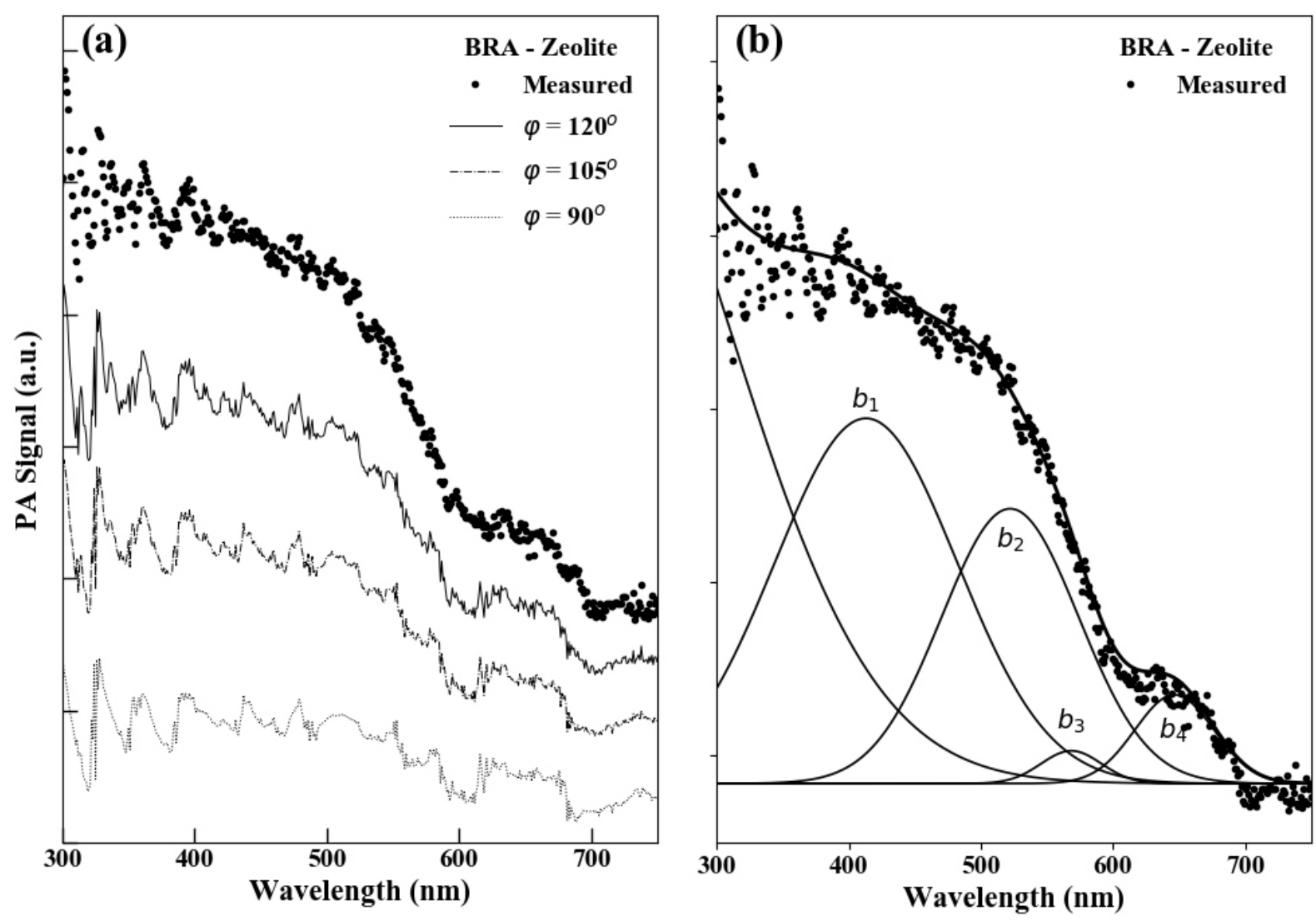

Figure 2. Photoacoustic absorption spectra of (a) BRA zeolite and after PRM application for three different $\varphi$ angles and (b) Gaussian curves representing the electronic transition of Fe ${ }^{+3}$ centered at $b_{1}=413 \mathrm{~nm}, \mathrm{~b}_{2}=522 \mathrm{~nm}, \mathrm{~b}_{3}=568$ $\mathrm{nm}$, and $\mathrm{b}_{4}=645 \mathrm{~nm}$.

signal amplitude Filho et al. (2009). Nonetheless, the latter discloses a constant PA phase as a function of modulation frequency. This PA phase behavior was never observed in our measurements. Thereby, the thermoelastic sample bending is the prevailing mechanism for the PA signal generation Perondi \& Miranda (1987), Rousset et al. (1983). The reason behind our assertion is shown in Figure 4 b, where the best fit for the PA phase is depicted as a function of modulation frequency for the Cuban zeolite according to Equation 2 Filho et al. (2009), Mota et al. (2010), leaving $\tau$ and $\tau_{\beta}$ to be adjusted.

$$
\vartheta=\frac{\pi}{2}-\operatorname{atan}[\omega \tau]-\operatorname{atan}\left[\frac{1}{\left(\sqrt{2 \omega \tau_{\beta}}-1\right)}\right],
$$

where $\omega=2 \pi f$. We refer to the works of César and Pessoa-Júnior (César et al. 1984, 1985, Pessoa-Júnior 1985) for a more detailed discussion on a modified Rosencwaig and Gersho theory. BRA- and CUB-zeolites revealed values of $\tau_{\mathrm{BRA}}=5.40 \mathrm{~ms}, \tau_{\mathrm{CUB}}=4.60 \mathrm{~ms}, \tau_{\beta \mathrm{BRA}}=387 \mu \mathrm{s}$ and $\tau_{\beta \mathrm{CUB}}=305$ $\mu \mathrm{s}$, being in close agreement with reported data found in literature for relaxation times ascribed to iron Manhães et al. (2002) and manganese Baesso et al. (1989) ions.

Additionally, with the help of Tanabe-Sugano diagrams Tanabe \& Sugano (1954), through the diagonalization of the energy matrices for $d 5$ configuration and adopting the same approach as 

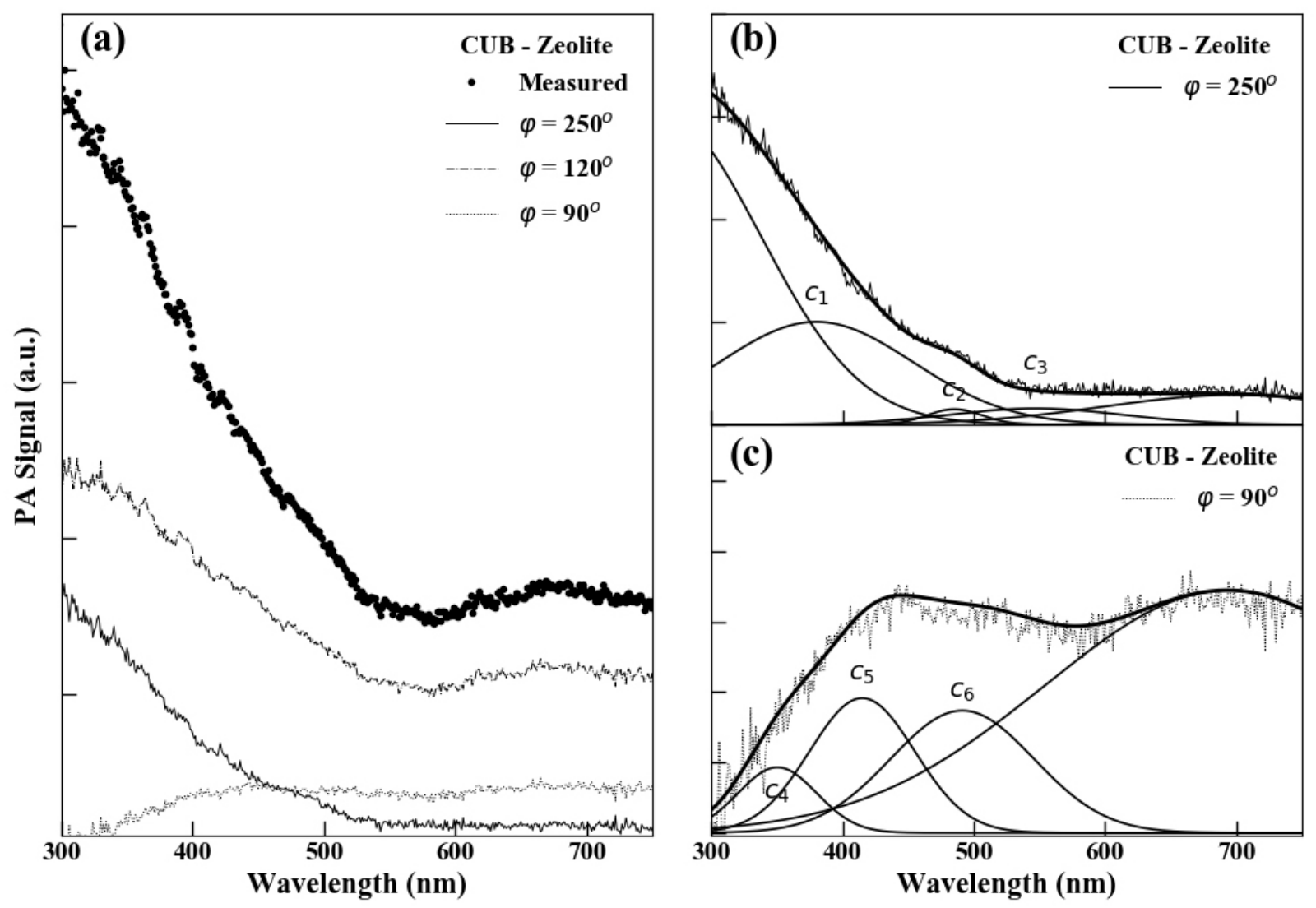

Figure 3. Photoacoustic absorption spectra of (a) CUB zeolite as measured and after PRM application for three different $\varphi$ angles, (b) Gaussian curves representing the electronic transitions of Fe centered at $\mathrm{c}_{1}=380 \mathrm{~nm}, \mathrm{c}_{2}=$ $485 \mathrm{~nm}$, and $\mathrm{c}_{3}=547 \mathrm{~nm}$, and (c) Gaussian curves representing the electronic transitions of $\mathrm{Mn}^{+2}$ (centered at $\mathrm{c}_{4}=$ $350 \mathrm{~nm}$ and $\left.\mathrm{C}_{5}=415 \mathrm{~nm}\right)$ and $\mathrm{Mn}^{+3}\left(\right.$ at $\left.\mathrm{C}_{6}=491 \mathrm{~nm}\right)$.

described by Kumar et al. (1996) and Pedro et al. (2009), the crystal field parameter (Dq) and the Racah interelectronic repulsion parameters ( $B$ and $C$ ) have been evaluated. Doing so, values of which gave us the best fit with observed data were found to be $D q=1048 \mathrm{~cm}^{-1}, B=457 \mathrm{~cm}^{-1}$ and $C=3655$ $\mathrm{cm}^{-1}$ for iron ions in BRA-zeolite and $\mathrm{Dq}=945 \mathrm{~cm}^{-1}, \mathrm{~B}=813 \mathrm{~cm}^{-1}$ and $\mathrm{C}=2496 \mathrm{~cm}^{-1}$ for iron ions in CUB-zeolite. The energy values used to assess these parameters were $24213 \mathrm{~cm}^{-1}, 19157 \mathrm{~cm}^{-1}$ and $15504 \mathrm{~cm}^{-1}$ for the BRA sample and $26316 \mathrm{~cm}^{-1}, 20619 \mathrm{~cm}^{-1}$ and $18282 \mathrm{~cm}^{-1}$ for the CUB sample. These results allow us to state that the $\mathrm{Fe}^{3+}$ ions are either tetrahedrally or octahedrally coordinated Hannoyer et al. (1992), Karickhoff (1973), Manhães et al. (2002), Pedro et al. (2009), Sosman et al. (1998), Gargori et al. (2017) into the zeolitic matrix.

Aluminosilicate raw materials, as the name suggests, are composed of superimposed layers of silica/alumina-rich tetrahedrons and octahedrons Cairns-Smith \& Hartman (1986), Partheniades (2009). Iron and manganese ions encountered through their skeleton might be as interstitial or substitutional impurities so that, if the $\mathrm{Fe}^{3+}$ replaces an $\mathrm{Al}^{3+}$ in an octahedral sheet, the balance of charges remains constant and no distortion is to be expected (isomorphous replacement) Joshi et al. (1993). However, if the $\mathrm{Fe}^{3+}$ substitutes a $\mathrm{Si}^{4+}$ in a tetrahedral site, some degree of distortion 

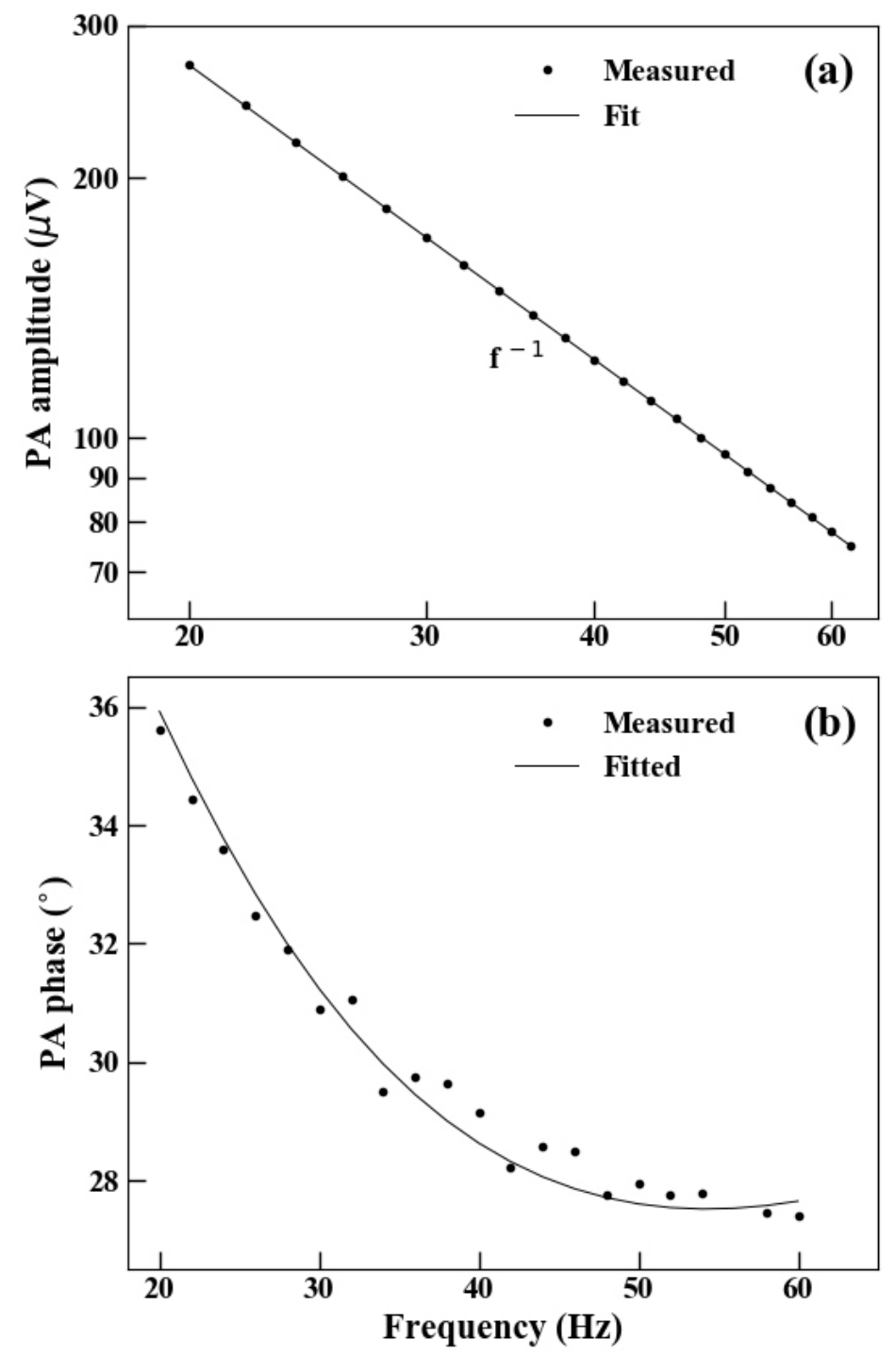

Figure 4. (a) Photoacoustic signal amplitude as a function of modulation frequency for the Cuban sample. The solid line corresponds to data fit to $\mathrm{f}^{-1}$ power law. (b) Photoacoustic phase as a function of modulation frequency for the Cuban sample. The solid line corresponds to the best fit according to Equation 2.

may be found due to the resulting unbalanced charges Meunier (2005). Concerning the $\mathrm{Mn}^{2+}$ ions, they can possibly be replacing a $\mathrm{Ca}^{2+}$ or $\mathrm{Mg}^{2+}$ ion into the mineral matrix Franco \& Rossi (2003), Gunasekaran \& Anbalagan (2008). Thus, to confirm that the chemical species $\mathrm{Fe}^{3+}$ and $\mathrm{Mn}^{2+}$ are present in Brazilian and Cuban zeolites, X- and Q- band EPR spectra from both samples were taken. For the ferric ion, when it is in a substitutional tetrahedrally coordinate original $\mathrm{Si}^{4+}$ position, the unbalanced charge yields low symmetry of the electric field of the $\mathrm{Fe}^{3+}$ environment. In this case, the spin Hamiltonian which represents the high-spin $\mathrm{Fe}^{3+},\left(\mathrm{d}_{5}, \mathrm{~S}=5 / 2\right)$, includes the Zeeman term and the zero field splitting (ZFS) one:

$$
\mathcal{H}_{S}=g \beta \mathbf{H} \cdot \mathbf{S}+D\left[\mathbf{S}_{z}^{2}-\frac{1}{3} \mathbf{S}(S+1)\right]+E\left(\mathbf{S}_{x}^{2}-\mathbf{S}_{y}^{2}\right),
$$

where $\beta$ is the Bohr magneton, $D$ and $E$ are the axial and the rhombic symmetry distortions parameters Mansanares et al. (1989), Goldfarb et al. (1994). 
Q-band measurements show better resolved spectra, thus allowing better identification of the present species; hence, only the Q-band are being presented. Figure 5 presents the measured Qband EPR spectrum for the BRA-zeolite and lines are attributed to $\mathrm{Fe}^{3+}$ ions, since $\mathrm{Fe}^{2+}$ ions are not usually observed at room temperature and, although some rare earth paramagnetic elements have been detected in some zeolites Rizo \& Peraza (1997), their concentrations are very small compared to those of the elements iron and manganese. Eventual rare earth resonance lines will be immersed in the much more intense lines of iron and manganese ions in our spectra. Moreover, rare earth EPR lines are generally detected at low temperatures and our experiments were performed at room temperature. No other paramagnetic species are supposed to be present. The experimental spectra were fitted by a sum of $n$ first derivatives of the Lorentzian equation Mota et al. (2009):

$$
\Gamma(\mathbf{H})=\sum_{i=1}^{n}-1,5396 A_{i}\left[\frac{\mathbf{H}-\mathbf{H}_{0 i}}{1 / 2 \Delta \mathbf{H}_{i}}\right]\left[1+\left(\frac{\mathbf{H}-\mathbf{H}_{0 i}}{1 / 2 \Delta \mathbf{H}_{i}}\right)^{2}\right]^{-2},
$$

where $\mathbf{H}$ is the applied external magnetic field, $A_{i}$ is the peak-to-peak signal amplitude, $\mathbf{H}_{0 i}$ is the magnetic resonance field and $\Delta \mathbf{H}_{i}$ is the peak-to-peak line width and $n$ is the adequate number of equations in each case of overlapped lines.

Looking at Figure 5a, the more intense line in the center of the spectrum was fitted by Equation 4 considering $n=2$, yielding two lines with g values of 2.11 (curve 1) and 2.03 (curve 2), attributed to $\mathrm{Fe}^{3+}$ ions in nondistorted octahedral environment Mota et al. (2009), Sengupta et al. (2010) either in interstitial zeolite network sites or in clusters structures due to strong interactions between iron ions Goldfarb et al. (1994), Soulayman et al. (2004). These are the main contributions to the spectrum. Figure $5 \mathrm{~b}$ shows the low field spectrum region (left side of Figure $5 \mathrm{a}$ from o $\mathrm{kG}$ to $10 \mathrm{kG}$ ). The presence of a weak line distribution at $\mathrm{g}$ values of 4.9, 3.3, 2.8, 2.6 and 2.4 (arrows from 3 to 7, respectively) was identified. For the sake of visualization, at $\approx 11.5 \mathrm{kG}$ arrow 8 indicates the sixth line, $g=2.12$, belonging to the aforementioned distribution (it is displayed in Figure $5 a$ and not in Figure $5 b$ just because of scale purposes). They correspond to $\mathrm{Fe}^{3+}$ ions in tetrahedral sites with strong rhombic distortion Mansanares et al. (1989), Berger et al. (1995). Diagonalizing $\mathcal{H}$, Equation 3, in the $S=5 / 2$ manifold we find three doublets whose energies depend upon the $D / E$ relation. Thus, one obtains the effective $g$ factors (gx, gy, gz) predictions for each doublet as a function of D/E Mansanares et al. (1989). Hence, the spectrum of Figure 5a shows a superposition of two main isotropic resonances and, at least, six powder spectra, for $\mathrm{Fe}^{3+}$ ions in octahedrally and tetrahedrally coordinated sites. The powder spectra are very weak compared with the isotropic two resonance lines. For this reason, the simulation involved only the octahedrally coordinated sites. In our case, we can verify from the prediction that each line detected would be followed by other lines occurring in the region of $g$ values between 10 and 5 . For this detected line distribution in tetrahedrally distorted sites, the D/E parameter varied between 8.5 and 6.1, indicating significant rhombic distortions (obtained from the g values predictions) Mansanares et al. (1989).

Figure 6a presents the measured Q-band EPR spectrum for Cuban zeolite, showing an intense line in the center of the spectrum and another weaker, shifted to higher field. The spectrum was fitted with $n=3$ in Equation 4, yielding lines with g values of 2.30 (curve 1), 2.21 (curve 2) and 2.00 (curve 3). The 2.30 and 2.21 resonances are attributed to $\mathrm{Fe}^{3+}$ ions in octahedrally coordinate sites, probably due to ferric ions clusters from migration of extra framework $\mathrm{Fe}^{3+}$ or even from dislodged framework ions 

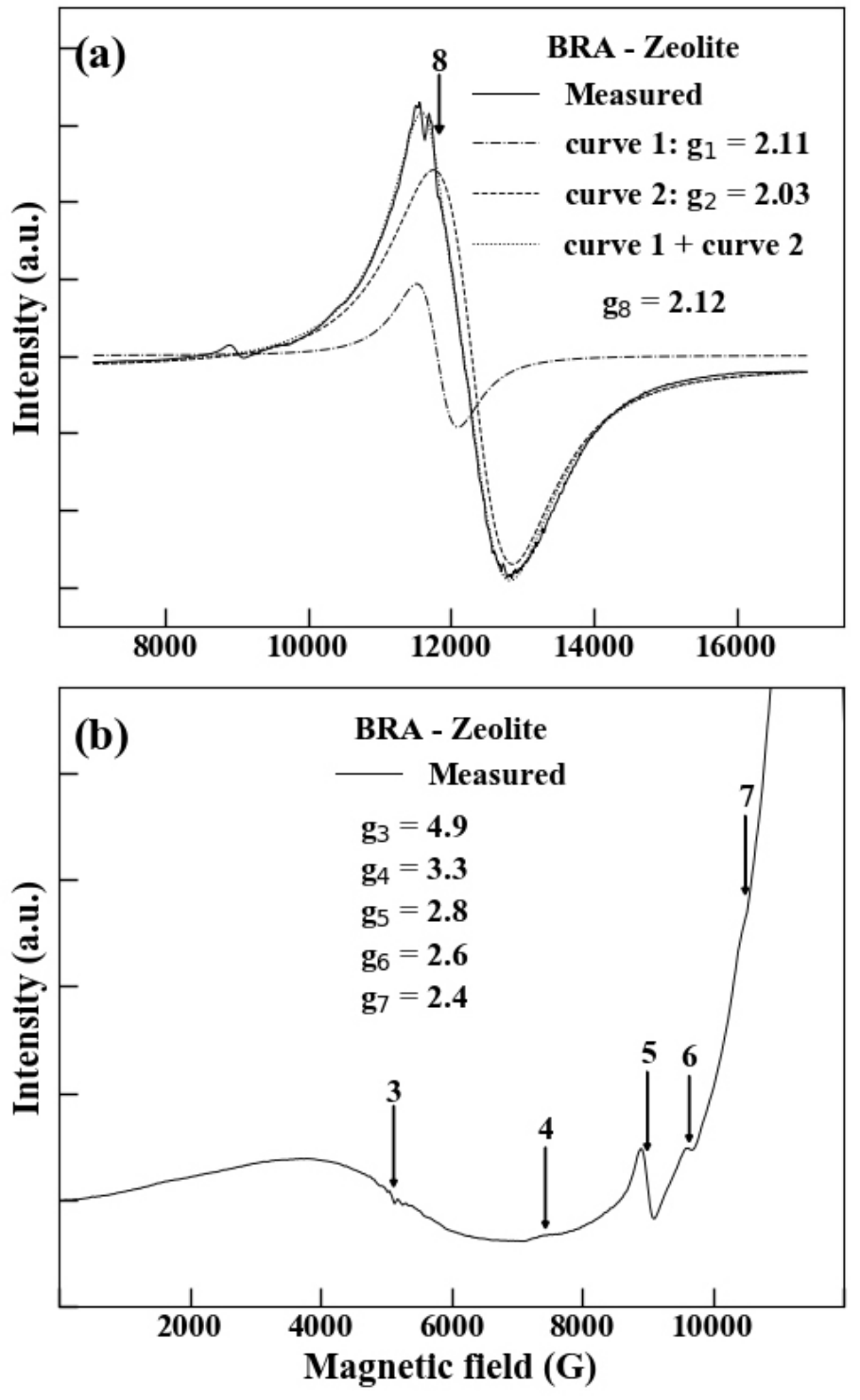

Figure 5. Room temperature Q-band EPR spectrum for the BRA-zeolite sample: (a) as measured spectrum and (b) low field spectrum region.

Goldfarb et al. (1994). The $g=2.00$ line, overlapping the $\mathrm{Fe}^{3+}$ line in the range between $12.2 \mathrm{kG}$ and 12.9 $\mathrm{kG}$, is the characteristic six hyperfine lines of $\mathrm{Mn}^{2+}$, occupying octahedral coordination Sengupta et al. (2010) as disclosed in Figure 6b. As discussed above for BRA-zeolite, here there is also no resolution to observe any rare earth magnetic ion resonance line.

As previously discussed by Franco and Rossi Franco \& Rossi (2003), if the sextet do not show equally spaced lines, it points out to a random orientation of $\mathrm{Mn}^{2+}$ ions located in environments with different crystalline fields. In our case the lines spacement differences do not exceed $3 \%$. Another interesting aspect concerns the magnitude of the isotropic hyperfine splitting constant $\left(A_{0}\right)$, which provides a qualitative measure of ionicity between the $\mathrm{Mn}^{2+}$ ions and their ligands van Wieringen 

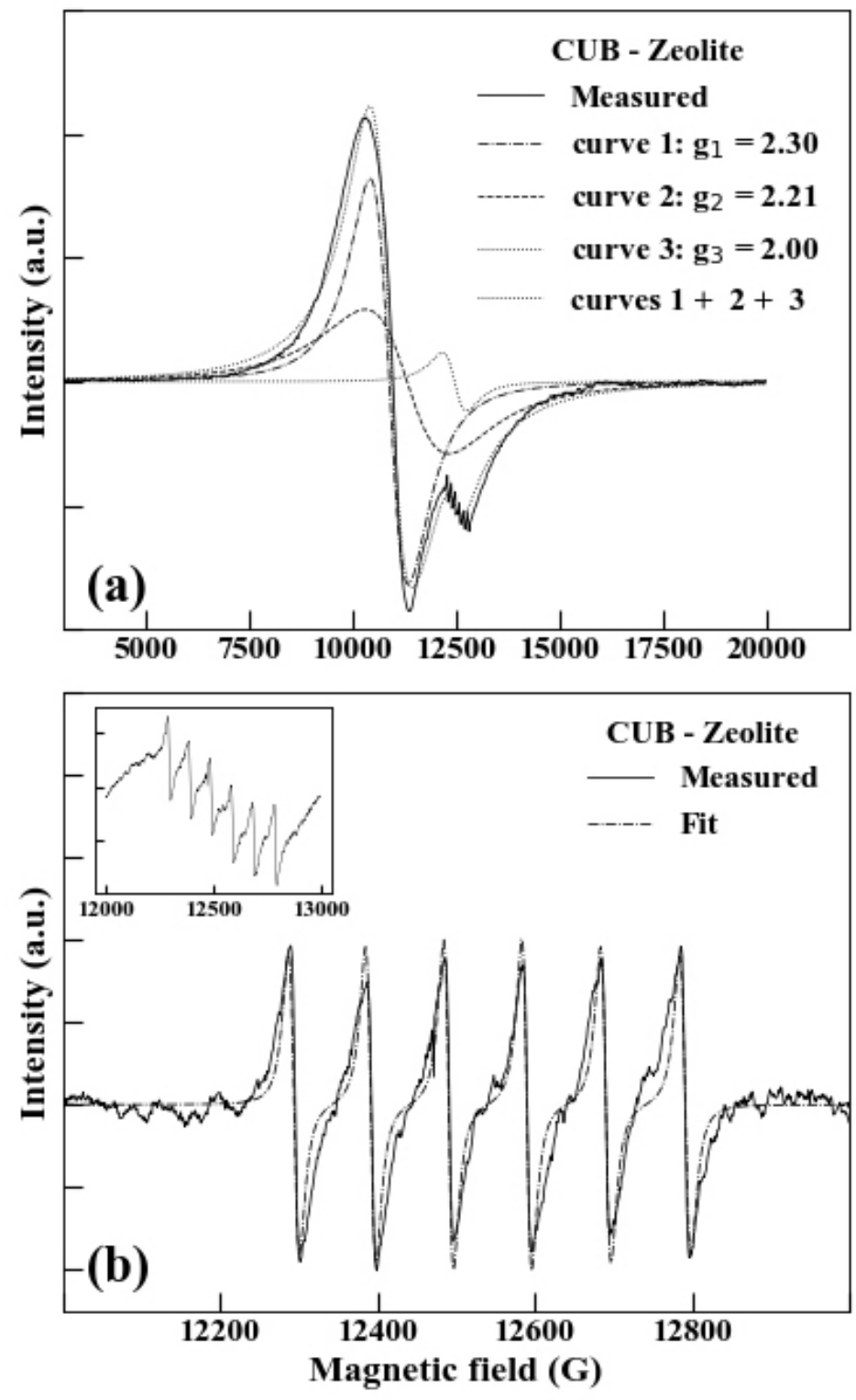

Figure 6. (a) Room temperature Q-band EPR spectra for the Cuban (CUB-zeolite) sample. (b) Six hyperfine lines of $\mathrm{Mn}^{2+}$ highlighted.

(1955). According to former publications Kumar et al. (1996), Chakradhar et al. (2005), this parameter can be calculated by means of the following equation:

$$
\mathbf{H}_{\mathrm{m}}=\mathbf{H}_{0}-A_{0} m-\left(\frac{A_{0}^{2}}{8 \mathbf{H}_{0}}\right)\left(35-4 m^{2}\right),
$$

where $\mathbf{H}_{\mathrm{m}}$ is the magnetic field corresponding to $\mathrm{m} \leftrightarrow \mathrm{m}$ hyperfine line, $\mathbf{H}_{0}$ is the manganese central resonance field and $m=-5 / 2,-3 / 2,-1 / 2,+1 / 2,+3 / 2$ and $+5 / 2$. A mean value was found to be $A_{0}=$ $9.7 \pm 0.7 \mathrm{mT}$, which suggests beyond an octahedral coordination due to the $\mathrm{g} \approx 2.00$, an ionic bonding character Soulayman et al. (2004), Chakradhar et al. (2005), Franco et al. (2006) of the $\mathrm{Mn}^{2+}$ ion and its surroundings. For comparison ends, Figure $6 \mathrm{~b}$ shows beyond the as measured spectrum (inset graph) 
and a simulation according to Equation 6 which includes the Zeeman term $(\mathrm{g} \beta \mathbf{H} \cdot \mathbf{S})$ and the hyperfine interaction term $\left(A_{0} \mathbf{I} \cdot \mathbf{S}\right)$.

In the simulation, we adopted both the manganese nuclear spin $\mathbf{I}$ and the electronic spin $\mathbf{S}$ as 5/2. To do so, a toolbox named EasySpin Stoll \& Schweiger (2006) was utilized. It permits not only a fine adjustment to the experimental data but also a baseline correction before simulation as clearly seen in Figure 6b. From the simulated curve, the parameter $A_{0}$ was found to be $9.6 \mathrm{mT}$, agreeing very well with that calculated by Equation 5 ( $9.7 \mathrm{mT}$ ). Also, the obtained $g$ value by Equation 6, 1.99, is in close agreement with that attained by Equation 4 (2.00).

$$
\mathcal{H}^{*}=g \beta \mathbf{H} \cdot \mathbf{S}+A_{0} \mathbf{I} \cdot \mathbf{S}
$$

From the collected data, we are also led to infer that the $\mathrm{Mn}^{2+}$ are partially replacing the $\mathrm{Ca}^{2+}$ ions Franco \& Rossi (2003) found within the Cuban zeolite Riter (2011) without loss of symmetry. An important feature of materials used to hold nitrogen fertilizer is its feasibility of making ion exchange. $\mathrm{NH}_{4}^{+}$is the typical ion present in artificial fertilizer and its incorporation inside micropores occur by its exchange with natural cations present in the zeolite structure. The presence of $\mathrm{Mn}^{2+}$ probably contribute to the CUB zeolite to hold $\mathrm{NH}_{4}^{+}$. This statement is corroborated by studies that show higher desorption rate of $\mathrm{NH}_{3}$ from CUB zeolite than BRA one Baptista-Filho et al. (2011).

\section{CONCLUSIONS}

BRA and CUB zeolites were investigated by photoacoustic phase resolved method and electron paramagnetic resonance spectroscopy. Photoacoustic technique was useful to single out the transition bands of iron and manganese ions. The presence of both ions were confirmed through $\tau$ and $\tau_{\beta}$ evaluation, whose values were found to be $\tau_{B R A}=5.40 \mathrm{~ms}, \tau_{C U B}=4.60 \mathrm{~ms}, \tau_{\beta B R A}=387 \mu \mathrm{s}$ and $\tau_{\beta C U B}=305 \mu \mathrm{s}$. The calculated Dq-${ }^{-}{ }_{B R A} / \mathrm{Dq}^{-}{ }_{\mathrm{CUB}}=1048 \mathrm{~cm}^{-1} / 945 \mathrm{~cm}^{-1}, \mathrm{~B}^{-}{ }_{\mathrm{BRA}} / \mathrm{B}^{-}{ }_{\mathrm{CUB}}=457 \mathrm{~cm}^{-1} / 813$ $\mathrm{cm}^{-1}$ and $\mathrm{C}^{-}{ }_{\mathrm{BRA}} / \mathrm{C}^{-}{ }_{\mathrm{CUB}}=3655 \mathrm{~cm}^{-1} / 2496 \mathrm{~cm}^{-1}$ parameters say, hitherto, that the $\mathrm{Fe}^{3+}$ ions are both tetrahedrally and octahedrally coordinated in the Brazilian zeolite. EPR spectra revealed the characteristic $g$ values attributed to $\mathrm{Fe}^{3+}$ in tetrahedral symmetry accompanied by rhombic distortion ( $g \approx 2.12,2.4,2.6,2.8,3.3$ and 4.9 for BRA zeolite) and octahedral ( $g=2.11$ and 2.03 for BRA and 2.30 and 2.21 for CUB zeolites) sites. $\mathrm{Mn}^{2+}$ ions, characterized by the six hyperfine lines, were found to be only in octahedral coordination $(g=2.00)$ substituting $\mathrm{Ca}^{2+}$ ions. Furthermore, the hyperfine splitting constant with a value of $A_{0}=9.7 \mathrm{mT}$ points towards an ionic bonding character of the $\mathrm{Mn}^{2+}$ ion and its vicinity. Thus, its important to emphasize that the main absorption and retention mechanism of mineral nitrogen $\left(\mathrm{NH}_{4}^{+}\right)$in zeolites is associated to the process of ion exchange, what makes the Cuban zeolite an interesting material to capture $\mathrm{NH}_{4}^{+}$in substitutional $\mathrm{Mn}^{2+}$ sites inside the micro-channels of the zeolite.

\section{Acknowledgments}

Arlem Lara-Bernal and E. Marin thank the support of CONACYT, COFAA and SIP-IPN, Mexico. T. C. Cordeiro appreciates the Post-Doc fellowship provided by UENF. The authors are also gratefully acknowledged to the Brazilian funding agencies FAPERJ (Fundação de Amparo à Pesquisa do Estado do Rio de Janeiro Carlos Chagas Filho) and CNPq (Conselho Nacional de Pesquisa). Luiz Antônio Meirelles and Israel Andrade Esquef deserve the credits for their most valuable technical assistance. 


\section{REFERENCES}

ALMOND DP \& PATEL PM. 1996. Photothermal Science and Techniques. Chapman \& Hall.

BAESSO ML, MANSANARES AM, DA SILVA EC, VARGAS $H$ \& MIRANDA LCM. 1989. Phase-resolved photoacoustic spectroscopy and EPR Investigation of $\mathrm{MnO}_{2}-$ and CoO-doped soda-lime glasses. Phys Rev B 40(3): 1880-1884

BAPTISTA-FILHO M. 2011. Developments on photoacoustic spectroscopy for trace gas detection of ammonia volatilized from nitrogen fertilizer. Ph.D. thesis. Laboratório de Ciências Físicas, Centro de Ciência e Tecnologia, Universidade Estadual do Norte Fluminense Darcy Ribeiro.

BAPTISTA-FILHO M ET AL. 2011. Ammonia traces detection based on photoacoustic spectroscopy for evaluating ammonia volatization from natural zeolites at typical crop field temperature. Sens Actuators B Chem 158: 241-245.

BERGER R, KLIAVA J, YAHIAOUI EM, BISSEY JC, ZINSOU PK \& BÉZIADE P. 1995. Diluted and non-diluted ferric ions in borate glasses studied by electron paramagnetic resonance. J Non Cryst Solids 180(2-3): 151-163.

BIYIK R \& TAPRAMAZ R. 2016. An EPR study of clinoptilolite from Bigadiç in Turkey. Microporous Mesoporous Mater 219: 38-41.

BRECK DW. 1974. Zeolite molecular sieves: structure, chemistry, and use. John Wiley \& Sons.

BUENO SCE, FILHO MB, JR PSGA, POLIDORO JC, OLIVARES FL, STHEL MS, VARGAS H, MOTA L \& DA SILVA MG. 2015 Cuban zeolite as ammonium carrier in urea-based fertilizer pellets: Photoacoustic-based sensor for monitoring $\mathrm{N}$-ammonia losses by volatilization in aqueous solutions. Sens Actuators B Chem 212: 35-40.

CAIRNS-SMITH AG \& HARTMAN H. 1986. Clay minerals and the origin of life. $1^{\text {st }}$ Ed. Cambridge University Press.

CÉSAR CL, VARGAS H, PELZL J \& MIRANDA LCM. 1984. Phase resolved photoacoustic microscopy: aplication to ferromagnetic resonance. J Appl Phys 55: 3460-3464.

CÉSAR CL, VARGAS H \& MIRANDA LCM. 1985. Photoacoustic microscopy of layered samples: phase detection technique. J Phys D: Applied Physics 18: 599-608.

CHAKRADHAR RPS, SIVARAMAIAH G, RAO JL \& GOPAL NO. 2005. EPR and optical investigations of manganese ions in alkali lead tetraborate glasses. Spectrochim Acta Part A 62: 761-768.
CORRÊA SF, MOTA L, PAIVA LB, DO COUTO FM, DA SILVA MG, DE OLIVEIRA JG, STHEL MS, VARGAS H \& MIKLÓS A. 2011. Effects of ozone exposure on "Golden" papaya fruit by photoacoustic phase-resolved method: physiological changes associated with carbon dioxide and ethylene emission rates during ripening. J Appl Phys 109: 114701(1)-114701(7)

DE C BERNARDI AC, OLIVIERA PPA, DE MELO MONTE MB \& SOUZA-BARROS F. 2013. Brazilian sedimentary zeolite use in agriculture. Microporous Mesoporous Mater 167: 16-21.

DIMOWA LT, PETROV OE, TARASOV MP \& KADIYSKI MK. 2017. Structural study of T1-exchanged natural clinoptilolite using Rietveld refinement. Bulg Chem Commun 49(A): 46-52.

DYER A. 1988. An introduction to zeolite molecular sieves. Wiley, Chichester.

EROGLU N, EMEKCI M \& ATHANASSIOU CG. 2017. Application of natural zeolites on agriculture and food production. J Sci Food Agric 97: 3487-3499.

FILHO NES, NOGUEIRA AC, ROHLING JH, BAESSO ML, MEDINA AN, SIQUEIRA APL, SAMPAIO JA, VARGAS $H$ \& BENTO AC. 2009. Investigation of doped calcium aluminosilicate glass: a coupling between thermal-expansion and thermal-diffusion models for assessment of nonradiative relaxation time and characteristic diffusion time. J Appl Phys 106(9): 093105(1)-093105(9).

FRANCO RWA \& ROSSI FPAM. 2003. Identification and valuation of paramagnetic radicals in natural dolomites as an indicator of geological events. Phys Chem Miner 30: 39-43.

FRANCO RWA, LIMA JF, MAGON CJ, DONOSO JP \& MESSADDEQ Y. 2006. Magnetic resonance study of the crystallization behavior of $\mathrm{InF}_{3}$-based glasses doped with $\mathrm{Cu}^{2+}, \mathrm{Mn}^{2+}$ and $\mathrm{Gd}^{3+}$. J Non Cryst Solids 352: 3414-3422.

GARGORI C, CERRO S, FAS N, LLUSAR M \& MONRÓS G. 2017. Red-brown ceramic pigments based on chromium doped ferrian armalcolite, effect of mineralizers. Ceram Int 43(7): 5490-5497.

GOLDFARB D, BERNARDO M, STROHMAIER KG, VAUGHAN DEW \& THOMANN H. 1994. Characterization of iron in zeolites by X-band and Q-band ESR, pulsed ESR, and UV-visible spectroscopies. Journal of the American Chemical Society 116: 6344-6353.

GUNASEKARAN S \& ANBALAGAN G. 2008. Spectroscopic study of phase transitions in natural calcite mineral. Spectrochim Acta Part A 69: 1246-1251. 
HANNOYER B, LENGLET M, DÜRR J \& CORTES R. 1992. Spectroscopic evidence of octahedral iron (III) in soda-lime silicate glasses. J Non Cryst Solids 151(3): 209-216.

JOSHI PN, AWATE SV \& SHIRALKAR VP. 1993. Partial isomorphous substitution of iron $\left(3^{+}\right)$in the LTL framework. J Phys Chem 97(38): 9749-9753.

KARICKHOFF SW. 1973. Optical absorption spectra of clay minerals. Clays Clay Miner 21(1): 59-70.

KRSTIĆ V, UROŠEVIĆ T \& PEŠOVSKI B. 2018. A review on adsorbents for treatment of water and wastewaters containing copper ions. Chem Eng Sci 192: 273-287.

KUMAR RR, RAO AS \& REDDY BCV. 1996. EPR and optical absorption of $\mathrm{Mn}^{2+}$ ions in ternary $\mathrm{K}_{2} \mathrm{SO}_{4}-\mathrm{Na}_{2} \mathrm{SO}_{4}-\mathrm{ZnSO}_{4}$ glasses. Transit Met Chem 21(5): 390-392.

LUNA FJ \& SCHUCHARDT U. 2001. Modificação de zeólitas para uso em catálise. Quim Nova 24(6): 885-892.

MANHÃES RST, AULER LT, STHEL MS, ALEXANDRE J, MASSUNAGA MSO, CARRIÓ JG, DOS SANTOS DR, DA SILVA EC, GARCIA-QUIROZ A \& VARGAS H. 2002. Soil characterisation using $\mathrm{X}$-ray diffraction, photoacoustic spectroscopy and electron paramagnetic resonance. Appl Clay Sci 21: 303-311.

MANSANARES AM, BAESSO ML, DA SILVA EC, GANDRA FCG, VARGAS H \& MIRANDA LCM. 1989. Photoacoustic and ESR studies of iron-doped soda-lime glasses-thermal diffusivity. Phys Rev B 40: 7912-7915.

MEUNIER A. 2005. Clays. $2^{\text {nd }}$ Ed. Springer-Verlag. 472 p.

MONTE MBM, MIDDEA A, PAIVA PRP, BERNARDI ACC, REZENDE NGAM, BAPTISTA-FILHO M, DA SILVA MG, VARGAS $H, A M O R I M ~ H S$ \& SOUZA-BARROS F. 2009. Nutrient release by a Brazilian sedimentary zeolite. An Acad Bras Cienc 81(4): 641-653.

MOTA L, TOLEDO R, MACHADO FAL, HOLANDA JNF, VARGAS $H$ \& FARIA-JÚNIOR RT. 2008. Thermal characterisation of red clay from the Northern Region of Rio de Janeiro State, Brazil using an open photoacoustic cell, in relation to structural changes on firing. Appl Clay Sci 42: 168-174.

MOTA L, TOLEDO R, JR RF, DA SILVA EC, VARGAS $H$ \& DELGADILLO-HOLTFORT I. 2009. Thermally treated soil clays as ceramic raw materials: characterization by $\mathrm{X}$-ray diffraction, photoacoustic spectroscopy and electron spin resonance. Appl Clay Sci 43: 243-247.

MOTA L, DA SILVA MG, DE SOUZA VP, VARGAS $H$ GUIMARÃES VF \& PAES-JÚNIOR HR. 2010. On the use of photoacoustic technique for monitoring the thermal properties of lanthanum strontium cobalt ferrite-yttria stabilized zirconia two-layer systems. Thin Solid Films 519: 938-942.

PARTHENIADES E. 2009. Cohesive sediments in open channels: properties, transport, and applications. $1^{\text {st }}$ Ed. Butterworth-Heinemann.

PEDRO SS, NAKAMURA O, BARTHEM RB \& SOSMAN LP. 2009. Photoluminescence and photoacoustic spectroscopies of $\mathrm{Fe}^{3+}$ in the $\mathrm{LiGa}_{5} \mathrm{O}_{8}-\mathrm{LiGaSiO}_{4}-\mathrm{Li}_{5} \mathrm{GaSi}_{2} \mathrm{O}_{8}$ system. J Fluoresc 19: 211-219.

PERONDI LF \& MIRANDA LCM. 1987. Minimal-volume photoacoustic cell measurement of the thermoelastic sample bending. J Appl Phys 62: 2955-2959.

PESSOA-JÚNIOR O. 1985. Aplicações de medidas de fase do efeito fotoacústico. Mestrado. Instituto de Física Gleb Wataghin, Universidade Estadual de Campinas.

RAVIKUMAR RVSSN, IKEDA K, CHANDRASEKHAR AV, REDDY YP, RAO PS \& YAMAUCHI J. 2003. Site symmetry of $\mathrm{Mn}(\mathrm{II})$ and $\mathrm{CO}(\mathrm{II})$ in zinc phosphate glass. J Phys Chem Solids 64: 2433-2436.

RITER HG. 2011. Caracterização física e química de granulados de compostos zeolíticos incorporados com ureia fertilizante para aplicação na agricultura. Master's thesis. Laboratório de Ciências Físicas, Centro de Ciência e Tecnologia, Universidade Estadual do Norte Fluminense Darcy Ribeiro.

RIZO OD \& PERAZA EFH. 1997. Multi-elemental characterization of Cuban natural zeolites. J Radioanal Nucl Chem 221(1-2): 255-258.

ROUSSET G, LEPOUTRE F \& BERTRAND L. 1983. Influence of thermoelastic bending on photoacoustic experiments related to measurements of thermal diffusivity of metals. J Appl Phys 54: 2383-2391.

SENGUPTA A, KADAM RM, RAJESWARI B, DHOBALE AR, BABU $Y$ \& GODBOLE SV. 2010. Characterization of Indian serpentine by $X$-ray diffraction, photoacoustic spectroscopy and electron paramagnetic resonance spectroscopy. Appl Clay Sci 50(3): 305-310.

SHAH GA, SHAH GM, RASHID MI, GROOT JCJ, TRAORE $B$ \& LANTINGA EA. 2018. Bedding additives reduce ammonia emission and improve crop N uptake after soil application of solid cattle manure. J Environ Manage 209: 195-204.

SOSMAN LP, ABRITTA T, AMARAL MR, CELLA N \& VARGAS H. 1998. Optical properties of LiGaTiO4: Fe3+. Solid State Communications 105(2): 135-138. 
SOULAYMAN SS, MKAMI HE \& SMITH GM. 2004. EPR investigation of two types of Syrian's natural zeolites. J Phys Chem Solids 65: 1779-1783.

STOCKER K, ELLERSDORFER M, LEHNER M \& RAITH JG. 2017. Characterization and utilization of natural zeolites in technical applications. Berg- und Hüttenmännische Monatshefte 162(4): 142-147.

STOLL S \& SCHWEIGER A. 2006. EasySpin, a comprehensive software package for spectral simulation and analysis in EPR. J Magn Reson 178(1): 42-55.

SUGANO S, TANABE Y \& KAMIMURA H. 1970. Multiplets of transitions-metal ions in crystals. Academic Press.

TANABE Y \& SUGANO S. 1954. On the absorption of complex ions. I. J Phys Soc Japan 9(5): 753-779.

TRAN YT, LEE J, KUMAR P, KIM KH \& LEE SS. 2019. Natural zeolite and its application in concrete composite production. Composites Part B: Engineering 165: 354-364.

VAN WIERINGEN JS. 1955. Paramagnetic resonance of divalent manganese incorporated in various lattices. Discussions of the Faraday Society 19: 118-126.

VARGAS H \& MIRANDA LCM. 1988. Photoacoustic and related photothermal techniques. Physics Reports 161: 43-101.

\section{How to cite}

LARA-BERNAL A, DA SILVA MG, MOTA L, MARÍN E, CORDEIRO TC, DA SILVA EC VIANA DA, VARGAS H, POLIDORO JC \& MONTE MBM. 2022. Characterization of Cuban and Brazilian natural zeolites by photoacoustic spectroscopy and electron paramagnetic resonance. An Acad Bras Cienc 94: e20200512. DOI 10.1590/0001-3765202120200512.

Manuscript received on April 9, 2020;

accepted for publication on August 10, 2020

\section{ARLEM LARA-BERNAL ${ }^{1}$}

https://orcid.org/0000-0001-7116-131X

MARCELO G. DA SILVA ${ }^{2}$

https://orcid.org/000-0001-5440-8245

\section{LEONARDO MOTA ${ }^{2}$}

https://orcid.org/0000-0002-5356-1309

\section{ERNESTO MARÍN ${ }^{1}$}

https://orcid.org/0000-00029443-7451

THALLIS C. CORDEIRO ${ }^{2}$

https://orcid.org/0000-0002-9813-8918

EDSON C. DA SILVA ${ }^{2}$

https://orcid.org/0000-0003-2749-4904
DANIEL A. VIANA ${ }^{2}$

https://orcid.org/0000-0001-8601-5593

\section{HELION VARGAS ${ }^{2}$}

https://orcid.org/0000-0003-4074-4701

\section{JOSÉ CARLOS POLIDORO 3}

https://orcid.org/0000-0003-4049-5768

MARISA BEZERRA DE MELLO-MONTE ${ }^{4}$

https://orcid.org/0000-0001-8089-2296

${ }^{1}$ Centro de Investigación en Ciencia Aplicada y Tecnología Avanzada, Instituto Politécnico Nacional, Legaria, 694, 11500 Colonia Irrigación, Mexico, D.F., Mexico

${ }^{2}$ Universidade Estadual do Norte Fluminense Darcy Ribeiro, Laboratório de Ciências Físicas, Centro de Ciência e Tecnologia, Avenida Alberto Lamego, 2000, 28013-602 Parque Califórnia, Campos dos Goytacazes, RJ, Brazil

${ }^{3}$ Empresa Brasileira de Pesquisa Agropecuária (EMBRAPA-Solos), Rua Jardim Botânico, 1024, 22460-000 Jardim Botânico, RJ, Brazil ${ }^{4}$ Centro de Tecnologia Mineral (CETEM), Avenida Pedro Calmon, 900, 21941-908 Ilha Universitária, RJ, Brazil

Correspondence to: Leonardo Mota

E-mail:mota@uenf.br

\section{Author contributions}

Arlem Lara-Bernal: Investigation, Data curation, Visualization; Marcelo Gomes da Silva: Data curation, Writing - review \& editing, Visualization; Leonardo Mota: Data curation, Roles/Writing - original draft; Conceptualization; Visualization; Ernesto Marín: Writing - review \& editing; Thallis Custódia Cordeiro: Investigation, Visualization; Edson Corrêa da Silva: Data curation, Roles/Writing - original draft; Writing - review \& editing; Daniel Alvarenga Viana: Investigation; Helion Vargas: Funding acquisition, Writing - review \& editing, Resources; José Carlos Polidoro and Marisa Bezerra de Mello-Monte: Sample preparation, Resources.

\section{(cc) BY}

